\title{
Prescription and Adherence to Statins of Patients with Coronary Artery Disease and Hypercholesterolemia
}

\author{
Antonio P. Mansur, André P. L. Mattar, Cristiane E. Tsubo, Danielle T. Simão, Fábio R. Yoshi, Kuang Daci \\ São Paulo, SP - Brazil
}

Objective -Statins have proved to be safe and effective in the secondary prevention of coronary artery disease, but the level of prescription and the reasons for nonadherence to treatment in many coronariopathy treatment centers has not been determined. The purpose of this study was to identify reasons for nonadherence to statin therapy.

Methods - We analyzed 207 consecutive patients with coronary artery disease and hypercholesterolemia (total cholesterol $\geq 200 \mathrm{mg} / \mathrm{dL}$ or $L D L$ - cholesterol $\geq 130 \mathrm{mg} / \mathrm{dL}$ ). Patients' average age was $61.7 \pm 10$ year; 111 (53.6\%) male were and 94 (46.6\%) were female. We analyzed the level of prescription and adherence to treatment with statins.

Results - Statins were prescribed for 139 (67\%) patients, but only 85 (41\%) used the drug. In spite of being indicated, statins were not prescribed in 68 (33\%) patients. Of 54 (26\%) patients, nonadherent to statins, $67 \%$ did not use the drug due to its high cost, $31 \%$ due to the lack of instruction, and only $2 \%$ due to side effects. Total cholesterol (260.3 \pm 42.2 vs $226.4 \pm 51.9 ; p<0.0001)$ and $L D L$

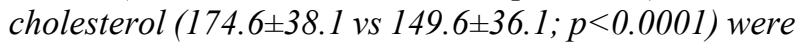
lower in patients on medication. $H D L-$ cholesterol increased from $37.6 \pm 9.6$ to $41.5 \pm 12.9 \mathrm{mg} / \mathrm{dL}(p=0.02)$, and triglycerides were not modified in patients using statins.

Conclusion - The prescription of statins in patients with coronary artery disease and dyslipidemia is high; however, its adherence is far from satisfactory, due to the high cost of the medication. Reduction in total cholesterol and $L D L$ cholesterol levels did not reach the targets recommended by the Brazilian Consensus on Dyslipidemia.

Keywords: coronary artery disease, hypercholesterolemia, statins, adherence.

Instituto do Coração do Hospital das Clínicas - FMUSP

Mailing address: Antonio P. Mansur - Av. Dr. Enéas C. Aguiar, 44 - 05403-000 São Paulo, SP - Brazil
Chronic diseases, such as arteriosclerosis, dyslipidemia, systemic arterial hypertension, and diabetes require prolonged clinical treatment, in most cases, for one's total life span. The patients with these diseases respond very well to nonpharmacological treatment, usually, dietary reorientation and adequate physical activity. However, in some patients, the addition of pharmacological treatment is necessary ${ }^{1,2}$. The medication is frequently used for a long period of time, when no side effects are observed. Although aware of the importance of the prescribed medication, many patients do not use it or use it irregularly ${ }^{3-6}$. This behavior is more noticeable in the aforementioned chronic diseases, because usually they are not associated with restricting acute symptoms. They are diseases that appear after long periods of exposure to noxious environmental influences. This problem is a fact for coronary heart disease patients as they live with a chronic problem, frequently associated with other known-risk factors for coronary heart disease ${ }^{7,8}$. As such, these patients should undergo appropriate pharmacological treatment, many times taking more than one medication. However, the prescription by physicians and the adherence to medication by coronary heart disease patients, followed up in terciary health care centers are unknown, as are the reasons that lead patients to nonadherence to the proposed treatment. This study chose hypercholesterolemia and pharmacological treatment with statins to analyze the level of prescription by physicians and the adherence of patients to this class of medication in a quaternary cardiology health care clinic.

\section{Methods}

We analyzed prospectively two hundred seven consecutive patients from the Coronariopathy Unit at the Heart Institute, Medical School, University of São Paulo (InCor). All patients with coronary heart disease and dyslipidemia (total cholesterol $>200 \mathrm{mg} / \mathrm{dL}$ or LDL-cholesterol $>130 \mathrm{mg} / \mathrm{dL}$ and triglycerides $<400 \mathrm{mg} / \mathrm{dL}$ ) from March to June ' 98 were included. Average age was from $28-83$ years (mean $\pm \mathrm{SD}$; $61.7 \pm 10$ ) years; $111(53.6 \%)$ were males and $96(46.4 \%)$ were 
females. Coronary heart disease diagnosis was obtained by angiography and defined as atherosclerotic lesions with over $50 \%$ occlusion in at least 1 epicardial coronary artery.

Tabagism, systemic arterial hypertension (diastolic arterial pressure $\geq 90 \mathrm{mmHg}$ ) ${ }^{9}$, and diabetes (glycemia $>126 \mathrm{mg} / \mathrm{dL}$ ) ${ }^{10}$ were prevalent. For diagnosis of hypercholesterolemia, total cholesterol values of $\geq 200 \mathrm{mg} / \mathrm{dL}$ or LDL cholesterol of $\geq 130 \mathrm{mg} / \mathrm{dL}$ were used. Hypercholesterolemia was the risk factor selected for this study-because 1) it is a chronic disease that in most cases is diagnosed in the laboratory, 2) it rarely causes symptoms that may influence conduct, 3) changes in its conduct are usually verified via blood tests, 4) it responds adequately to treatment that takes a few weeks, 5) it can be treated efficiently and safely with statins, 6) treatment with the regular use of medication is associated with significant lowering of cholesterol levels.

The level of prescription and adherence to statins by patients were analyzed according to the Brazilian Consensus on Dyslipidemia ${ }^{11}$. Nonadherence was classified as 1) lack of understanding by patients of the physician's instructions for taking the medication, for example use the statins for only a month, take the statins on alternate days, stop taking the statin after normalization of the cholesterol levels, among other things, 2) due to side effects, considering all those described for the medication, 3) nonutilization of the medication, in spite of having the prescription. In this case, the motives were questioned.

Serum triglyceride levels, total cholesterol, HDL-cholesterol, and LDL -cholesterol were analyzed in all patients, before and after the prescription or nonprescription of statins, average of $6.1 \pm 1.4$ months.

The statistical analysis was performed with the chi-square test for categorical variables and the Student's $t$ test for analysis of fractions that compose the lipid profile. Statistically significant values were $\mathrm{p}<0.05$.

\section{Results}

The clinical characteristics of patients are provided in Table I. Statins were prescribed for 139 (67\%) patients. Simvastatin, atorvastatin, and pravastatin were prescribed, respectively, for $72 \%, 21 \%$, and $7 \%$ of the patients who received a prescription. Eighty-five $(41 \%)$ took the medication regularly, while the remaining $122(59 \%)$ did not take the medication or took it irregularly. In 68 (33\%) patients, in spite of being indicated, statins were not prescribed. Irregular use of the medication was observed in 54 (26\%) of patients (fig.1). In these patients, the cost of the medication was mainly responsible for nonadherence; in $17(31 \%)$ it was due to lack of proper instruction on the use of the drug, and in 1 $(2 \%)$ it was due to side effects, in particular myalgia. Total cholesterol was lowered from $260.3 \pm 42.2$ to $226.4 \pm 51.9 \mathrm{mg} /$ $\mathrm{dL}(\mathrm{p}<0.0001)$ and LDL cholesterol from 174.6 \pm 38.1 to $149.6 \pm 36.1 \mathrm{mg} / \mathrm{dL}(\mathrm{p}<0.0001)$ in patients who used statins regularly. HDL-cholesterol increased from $37.6 \pm 9.6$ to $41.5 \pm 12.9 \mathrm{mg} / \mathrm{dL}(\mathrm{p}+0.02)$, and triglycerides were not modified in patients using statins. Serum triglyceride levels, total cholesterol, HDL-cholesterol, and LDL cholesterol were similar in groups of patients who did not use the medication or who used it irregularly (Table II).

\section{Discussion}

Prescription of statins in hypercholesterolemia treatment was effective in practically $70 \%$ of patients with coronary heart disease, which shows the awareness of attending physicians of the need to control this risk factor, selected for analysis of adherence in this study. However, for a significant number of patients, this knowledge was not transmitted adequately. This information should be better explained to the patient by the health worker, not necessarily by the

\begin{tabular}{|lcc|}
\hline \multicolumn{3}{|c|}{ Table I - Clinical characteristics of patients adherent or } \\
nonadherent to statins. \\
\hline N (207) & Adherent(85) & Nonadherent (122) \\
\hline Age (year) & $60.4 \pm 9.8$ & $61 \pm 11$ \\
Gender (M/F)* & $36 / 33$ & $74 / 64$ \\
Tabagism & $27(32 \%)$ & $43(35 \%)$ \\
SAH & $44(52 \%)$ & $61(50 \%)$ \\
Diabetes mellitus & $15(17 \%)$ & $13(16 \%)$ \\
Triglyceride(mg/dl) & $222.1 \pm 58.2$ & $232 \pm 64,4$ \\
Total cholestero (mg/dl) & $260.3 \pm 42.2$ & $245.6 \pm 55.3$ \\
HDL - cholesterol (mg/dl) & $37.6 \pm 9.6$ & $38.3 \pm 8.6$ \\
LDL - cholesterol (mg/dl) & $174.6 \pm 38.1$ & $176.2 \pm 31$ \\
\hline M- male; F- female; SAH- systemic arterial hypertension. \\
\hline
\end{tabular}

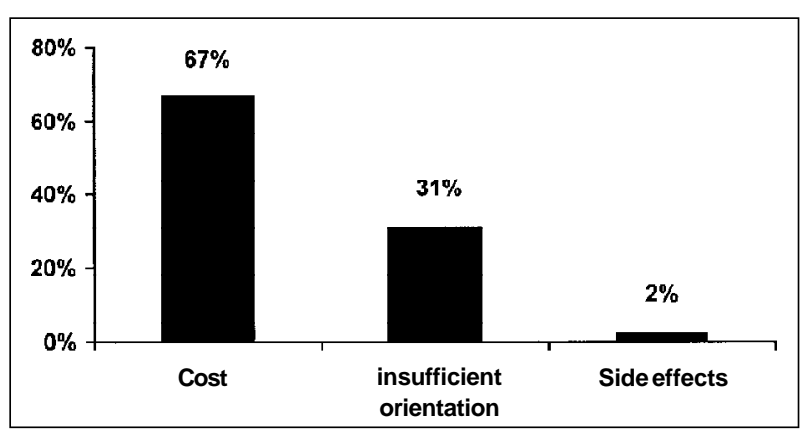

Figure 1-Motives for patient nonadherence to statins

\begin{tabular}{|c|c|c|c|}
\hline \multicolumn{4}{|c|}{$\begin{array}{l}\text { Table II - Lipid profile of patient adherent or nonadherent to } \\
\text { statins }\end{array}$} \\
\hline \multirow[t]{2}{*}{ Adherent $(\mathrm{N}=85)$} & & & \\
\hline & Initial & Final & $\mathrm{p}$ \\
\hline Triglyceride(mg/dl) & $222.1 \pm 58.2$ & $218.2 \pm 48.6$ & 0.636 \\
\hline Total cholesterol (mg/dl) & $260.3 \pm 42.2$ & $226.4 \pm 51.9$ & $<0.0001$ \\
\hline HDL - cholesterol $(\mathrm{mg} / \mathrm{dl})$ & $37.6 \pm 9.6$ & $41.5 \pm 12.9$ & 0.027 \\
\hline LDL-cholesterol (mg/dl) & $174.6 \pm 38.1$ & $149.6 \pm 36.1$ & $<0.0001$ \\
\hline \multicolumn{4}{|l|}{ Non-adherent $(\mathrm{N}=122)$} \\
\hline Triglyceride(mg/dl) & $232 \pm 55.3$ & $229 \pm 72.5$ & 0.717 \\
\hline Total cholesterol (mg/dl) & $245.6 \pm 55.3$ & $246.3 \pm 49$ & 0.917 \\
\hline HDL cholesterol (mg/dl) & $38.3 \pm 8.6$ & $38.6 \pm 10.1$ & 0.803 \\
\hline LDL cholesterol (mg/dl) & $176.2 \pm 31$ & $179.4 \pm 39.2$ & 0.480 \\
\hline
\end{tabular}


physician. Nurses, nutritionists, and pharmacists are examples of health workers who can also satisfactorily transmit information to improve patient adherence in the control of risk factors ${ }^{12,13}$. This, because chronic diseases are associated with more complex variables that interfere with patients' adherence to treatment, and often patients have doubts about their own understanding of the meaning of "coronary disease", of risk factors, of the necessity for long-term treatment, of the cost-benefit relation ratio of the treatment, and other things. Lack of information favors nonadherence to treatment and can stimulate the patient to try unconventional or nonevidence-based therapeutics. To avoid these problems, information transmitted to patients should be clear and objective, which is not always possible for the physician. Reasons for this situation transcends the scientific language and the physician-patient relationship, the latter more and more affected by the physicians' actual work situation. In this study, patient nonadherence due to side effects was very low and similar to the prevalence observed in some multicenter studies. It is known that statins are efficient and safe. The most frequent side effects are the increase of liver enzymes and myalgia ${ }^{14}$. However in this study, the most important factor of patient nonadherence to statins was the cost of statins, a problem also observed in other countries ${ }^{15-17}$. This fact is extremely important as it is known that the use of these medications reduces the prevalence of new cardiovascular events, as much in primary as in secondary prevention ${ }^{18}$. In coronary heart disease patients, a further reduction in serum levels of LDL cholesterol, to less than $100 \mathrm{mg} / \mathrm{dL}^{11}$ has been proposed. It is also known that for patients with stable coronary heart disease, besides statins, acetylsalicylic acid and beta-blockers are other medications that reduce morbidity and mortality, and these latter 2 medications are more reasonably priced for our population, thus promote better adherence. So that prescription of this triad of medications becomes a reality, urgent discussions regarding the price of statins is are necessary. Because cardiovascular diseases, ischemia, and stroke are the main causes of death in the Brazilian population, they are important public health issues.

Adherence to treatment depends on various factors related or not to patients' wishes. One of these factors of nonadherence is the inadequate communication between health care workers and patients, resulting in the patient's incapabilit of following medical recommendations, a fact more evident in older or semiilliterate patients ${ }^{19}$. However, the main restricting factor of chronic or long-term use is the cost of the medication.

It is important to note that, in spite of reductions in serum cholesterol and serum LDL-cholesterol levels, as an average, the levels recommended by the Brazilian Consensus on Dyslipidemia were not reached. To reach these goals in the long-term would signify a decrease in morbidity and mortality due to cardiovascular diseases in the population under study.

Other risk factors, such as arterial hypertension and diabetes, were not selected for this study, as they are potentially unstable diseases and could require alterations or changes in medications therefore causing increased side effects and decreased adherence. A global analysis of adherence, from a medical or socioeconomic point of view, would be affected.

In conclusion, the prevalence of the prescription of statins for patients with coronary heart disease and dyslipidemia is high, suggesting recognition, by the medical community of the drug's efficiency. In spite of the ample prescription of statins, adherence to their use is still far from satisfactory, mainly due to the high cost of the medication. At the same time, the reduction in total cholesterol and LDLcholesterol did not reach the levels recommended by the Brazilian Consensus on Dyslipidemia.

\section{Acknowledgements}

To Drs. Ângela Raineri, Desidério Favarato, José R.M. Martins.

\section{References}

1. Denke MA. Diet and lifestyle modification and its relationship to atherosclerosis. Med Clin North Am 1994; 78: 197-223.

2. Brown $\mathrm{AD}$, Garber AM. Cost effectiveness of coronary heart disease prevention strategies in adults. Pharmacoeconomics 1998; 14: 27-48.

3. Mansur AP, Gomes EPSG, Favarato D, Raineri A, Martins JRM, Ramires JAF. Tratamento medicamentoso da doença arterial coronariana estável em centros de atendimento primário e terciário. Arq Bras Cardiol 1997; 69: 165-8.

4. McDermott MM, Schmitt B, Wallner E. Impact of medication nonadherence on coronary heart disease outcomes. A critical review. Arch Intern Med 1997; 157: 1921-9.

5. Campbell NC, Thain J, Deans HG, Ritchie LD, Rrawles JM. Secondary prevention in coronary heart disease: baseline survey of provision in general practice. $\mathrm{Br}$ Med J 1998; 316: 1430-4.

6. Campbell NC, Thain J, Deans HG, Ritchie LD, Rawles JM, Squair J. Secondary prevention clinics for coronary heart disease: randomised trial of effect on health. Br Med J 1998; 316: 1434-7

7. Mansur AP, Gomes EPSG, Avakian SD, et al. Clustering of traditional risk factors in women with stable coronary artery disease. Cardiovasc Risk Factors (no prelo).

8. EUROASPIRE. A European Society of Cardiology survey of secondary pre- vention of coronary heart disease: principal results. EUROASPIRE Study Group. European Action on Secondary Prevention through Intervention to Reduce Events. Eur Heart J 1997; 18: 1569-82

9. III Consenso Brasileiro de Hipertensão. Rev Bras Cardiol 1999; 3: 96-100.

10. American Diabetes Association: clinical practice recommendations 1999. Diabetes Care 1999; 22(suppl 1): S1-114.

11. Consenso Brasileiro Sobre Dislipidemias: Detecção, Avaliação e Tratamento. Arq Bras Cardiol 1996; 67: 113-28.

12. Smith SC Jr. The challenge of risk reduction therapy for cardiovascular disease Am Fam Physician 1997; 55: 491-500.

13. Becker DM, Raqueno JV, Yook RM, et al. Nurse-mediated cholesterol management compared with enhanced primary care in siblings of individuals with premature coronary disease. Arch Intern Med 1998; 158: 1533-9.

14. Pedersen TR, Berg K, Cook TJ, et al. Safety and tolerability of cholesterol lowering with simvastatin during 5 years in the Scandinavian Simvastatin Survival Study. Arch Intern Med 1996; 156: 2085-92.

15. Goldman L, Weinstein MC, Goldman PA, Williams LW. Cost-effectiveness of 
HMG-CoA reductase inhibition for primary and secondary prevention of coronary heart disease. JAMA 1991; 265: 1145-51.

16. Troche CJ, Tacke J, Hinzpeter B, Danner M, Lauterbach KW. Cost-effectiveness of primary and secondary prevention in cardiovascular diseases. Eur Heart J 1998; 19(suppl C): 59-65.

17. Pickin DM, McCabe CJ, Ramsay LE, et al. Cost effectiveness of HMG-CoA re- ductase inhibitor (statin) treatment related to the risk of coronary heart disease and cost of drug treatment. Heart 1999; 82: 325-32.

18. Bucher HC, Griffith LE, Guyatt GH Systematic review on the risk cholesterollowering interventions. Arterioscler Thromb Vasc Biol 1999; 19: 187-95.

19. Morrow D, Leirer V, Sheikh J. Adherence and medication instructions. Review and recomendations. J Am Geriatr Soc 1988; 36: 1147-60. 